\title{
The FUTURES of Technical Services
}

THe 53RD ANNUAL RBMS PreConference in San Diego explored the variety of futures in store for the rare books, manuscripts, and special collections community. Technical Services, with its crucial roles in acquisitions, description, access, and preservation, will not be excepted from the changes headed our way. Even the very term technical services faces an uncertain future. At the University of California, "technical services" as a concept is being phased out in favor of the more encompassing "collection services," which covers the entire life cycle of library materials up until the moment they are shelved or made otherwise available to the research public.

The past of technical services is long and well defined. The descriptive standard of Anglo-American Cataloguing Rules (AACR2, and its predecessor AACR) has been nearly universally accepted worldwide as the way to describe the carriers of information, whether they are books, journals, maps, music, media, or digital files living on the Internet. For the rare materials cataloging community, the evolution and expansion of AACR's guidelines for describing early materials into Descriptive Cataloging of Rare Materials (DCRM, and its predecessors DCRB and BDRB) provide a framework for enhanced description of early, rare, and otherwise special materials that meets the needs of the specialized research community that relies on access to those materials.

But has the time come for major changes in the description and access of information? Clearly, for description, the answer is a resounding yes. Resource Description and Access (RDA) has been formally adopted by the Library of Congress as the successor to AACR2, and libraries nationwide are following suit. What role will linked data play in the library catalogs of the future? What role is it playing now? And, whither MARC? The MARC standard has been the de facto carrier of descriptive bibliographic metadata since the early 1970s. MARC has greatly evolved and expanded over the decades (and continues to do so), and, although reports of its death have been a part of the library landscape for many years, it remains a remarkably robust data standard. Is the Library of Congress's Bibliographic Framework really going to supplant it? 
The plenaries, seminars, discussion groups, short papers, and workshops presented at FUTURES! explored many of these questions ...

\section{Technical Services and Digital Humanities}

The topic of Digital Humanities (and Social Sciences) has been a ubiquitous one at recent conferences, and this is no less true of the RBMS preconference in San Diego. The opening plenary, "Use," on Digital Humanities featured two wellknown practitioners in this field, Bethany Nowviskie of the University of Virginia and Matthew G. Kirschenbaum of the University of Maryland. For those of us who have been working in the digital library and digital collection realm for many years, Bethany's discussion of the origins and long history of digital humanities was no surprise. Digitized library and special collection materials, largely created and managed by the technical services arm of the library, have been the source content used by digital humanists and digital librarians to carry out their work since the late 1980s. As a speaker at one of the ACH-ALLC programs in 1999, one of the present authors was exposed to the digital tools and technologies being used to support research and scholarly exploration in what was then called linguistic and humanities computing. This work encompassed not only textual materials, but also still images, moving images, databases, and geographic materials - the stuff upon which current digital humanities and social sciences efforts are still based. What she learned then-and what the plenary speakers confirmed at this conference-is that this work has and continues to be collaborative and interdisciplinary. Long-established humanities computing centers at the Universities of Virginia and Maryland have supported this work for years, and they have had a natural partner in the library and, more specifically, within the technical services departments that support acquisition, description, and digitization. Over the years, humanities computing centers have continued to evolve, often set within or supported by the library, and the field that is now known as Digital Humanities has gained prominence. The fact that this plenary opened the conference indicates that this work is on the rise.

As scholars' work is increasingly focused on digital materials, either digitized from physical collections or born digital, we are seeing more demand for digital content and tools to carry out digital analysis, visualization, and computational processing, among other activities. Perhaps this is due to the maturation of the field of humanities computing, or the availability of more digital source content, or the rise of a new generation of digital native researchers. Whatever the reason, the role of the library (and the archive and the museum, for that matter) is central to this work. The library is an obvious source of digital materials for these scholars to work with, as was pointed out by both speakers. 
Technical services librarians can play a central role in providing access to this content through traditional activities, such as cataloging of digital materials, supporting digitization initiatives, and acquisition of digital content, as well as taking on new activities, such as supporting technology solutions (like digital tools), providing digital lab workspaces, and facilitating bulk access to data and content through mechanisms such as APIs. Just as we have built and facilitated access to analog research materials, we need to turn our attention to building and supporting use of digital research collections.

As Bethany stressed in her talk, we need more digital content for these scholars to work with and use. Digital humanities centers can partner with libraries to increase the scale of digitized materials in special collections or can give us tools to work with born-digital archives from preacquisition assessment through access to users, such as the tools being developed by Matthew's "Bit Curator" project. ${ }^{1}$ By providing more content and taking the "magic" out of working with digital content, greater use can be facilitated. Unlike with physical materials, as Bethany pointed out, digital materials require use to remain viable, so the more we use digital materials, the longer they will last. She referred to this as "tactical preservation," saying that our digital materials should be "bright keys," in that the more they are used the brighter they become. By increasing use-making it easier to access and work with digital materials-we can ensure digital "futures" for our collections, whether physical or born digital.

The collaborative nature of Digital Humanities projects and centers brings together practitioners, technologists, tools, and content. These "places" may take various forms; but, in almost all cases, the library and the historical content it collects and preserves play central roles as the "stuff" of which digital humanities research and scholarly production is made. In keeping with our new role as "collection services," we on the technical side of the library are well positioned to support this work and become even more active partners in the Digital Humanities.

\section{Linked Data}

Perhaps only second to Digital Humanities in being ubiquitous on conference programs this year has been the topic of linked data. Whether discussing linked data in libraries or the linked open data movement, the key feature of this technology is that it is not coming from our own community but rather from the community of the Internet. The concept of linked data is one wherein bits of data are linked together through a series of Internet protocols so that those linkages can be understood and processed by a machine. The promise of linked data is that it will enable improved processing of information resources, enhance discovery and access, and, ideally, reduce the amount of work that catalogers will need to do in the future.

1. BitCurator: Tools for Digital Forensic Methods and Workflows in Real-World Collecting Institutions, available online at www.bitcurator.net/ [accessed 25 January 2013]. 
The discussions at the preconference largely surrounded what linked data means to us as librarians and, more pointedly, as catalogers. This question was addressed in the second plenary session, "Discovery," by Jon Voss of HistoryPin and Michael Panzer of OCLC, and then followed up on in the seminar, "Introduction to Linked Data: Connecting Our Collections," by speakers Regan Kladstrup from the University of Pennsylvania, Adrian Turner and Brian Tingle from the California Digital Library, and Katherine Wisser from the Simmons Graduate School of Library and Information Science. Jon discussed the Linked Open Data movement in terms of cultural expectations (that is, what users expect to be able to do with our data), legal constraints (in other words, what we can and cannot allow users to do with our data), and then gave an overview of the technology behind linked data. He advocated open access to these data to support new forms of expression, scholarship, and remixing of the data. Michael followed by discussing the technology and how linked data will change the way we think about describing materials, moving us from the complex, meaningful, and highly specific records we currently create, to records built on relationships between entities, assembled from linked data bits, that specify or disambiguate through known data values. So, instead of trying to specify in a record which exact author we are describing, we simply point to a known value representing that specific author and thereby say, "This is who I mean." This knowledge statement is specified through a linked data relationship.

What this means to technical services or "collection services," however, will still need to play out. We know that RDA was designed for a linked data environment, where catalogers identify entities as opposed to describing them. We also know (though it was not formally announced before the conference) that the new bibliographic framework model BIBFRAME, currently under development at the Library of Congress, will be a linked data model to function in the network environment, as opposed to only within our library systems. This will allow web-scale discovery through semantic search engines, to more easily and accurately get our materials to the end user. Technical services professionals can and should be involved in this work and understand their role in how it will function.

If we think of our records as bits of data that can be assembled, disassembled, and reassembled, repeatedly, they become building blocks that we can use and reuse. Our records now exist in structured sets of relationships — an author wrote a book, a book was published by a company, that company was located in a city, and so on. By breaking our records into simple relationships—called "triples" because they have three parts: a subject (author), predicate (wrote), and object (book)—computers can more easily traverse them and make connections for us. By using a known value for a city name or an author name, we need not qualify the data in our records as we often do now. Rather, we simply point to the known value (such as 
a name record in VIAF with its own identifier and URI). This authoritative linking should reduce the amount of work required to describe materials and bring the work of a cataloger into a new environment, one that makes more usable (by this we mean more able to be processed by machine) and explicit connections between things. The best part is that we can use the structured data we already have to get this rolling.

Because the use of a linked data model will make explicit connections between data, it will be easier to bring together data that live in separate systems, such as an integrated library system vs. a collection management system or like materials in different repositories. For those of us in technical services departments that manage multiple collection information systems, linked data offers the possibility of greater data unity across our collections and, ultimately, greater connections to collections held by others.

Examples of this work were discussed in the seminar on linked data, where the speakers discussed projects that are using linked data to connect collections. The Penn Provenance Project at University of Pennsylvania ${ }^{2}$ and the Social Network and Archival Context (SNAC) project ${ }^{3}$ are using linked data to make linkages between people and collections. Katherine Wisser discussed some of the issues that may arise when making these linkages or relationships based on archival description (or other descriptive practices), and how we should approach developing best practices for making these linkages and how to determine or qualify the significance of those relationships. There was some discussion on the role of the librarian in qualifying connections, but it seemed possibly that the qualification of relationships between entities could be made clear through visualization techniques or some form of defined practice, yet to be determined. The question of the role of technical services staff and librarians, on one hand, and crowd-sourcing these linkages through scholars or online communities, on the other, was discussed briefly. It seems clear that the role of technical services is still to be defined. Will we be involved in making linkages and, if so, will we be involved in qualifying those links? We should keep an eye on these projects, and the "Small World Project" at Simmons, for direction. ${ }^{4}$ At the end of the day, however, this work is all about, as Brian Tingle put it, "getting users to the good stuff"- -and we all want that.

2. Penn Provenance Project, available online at www.flickr.com/photos/58558794@N07/collections / $72157626385042757 /$ [accessed 25 January 2013].

3. Social Networks and Archival Context (SNAC) Project, available online at http://socialarchive. iath.virginia.edu/ [accessed 25 January 2013].

4. Small World Project: Investigating the "Small World" of Literary Archival Collections: The Impact of EAC-CPF on Archival Descriptive Practices, Simmons College, available online at http:/ / gslis. simmons.edu/smallworld/ [accessed 25 January 2013]. 


\section{RDA}

Perhaps the future that seems the closest at hand to rare materials catalogers is the advent of Resource Description and Access (RDA). Although RDA has been in development for many, many years, it is now well and truly upon us. The Library of Congress has formally adopted RDA as its official cataloging standard, replacing AACR2. While the rare materials cataloging community has kept a close watch on the development of RDA - the RBMS Bibliographic Standards Committee (BSC) has been submitting formal comments on the RDA development process since at least as far back as 2007-and has been developing DCRM to be compatible whenever possible, the time has now come to get fully on board the RDA bandwagon.

The discussion session sponsored by the Bibliographic Standards Committee, "The Future of Rare Materials Cataloging Standards: Can DCRM and RDA Get Along?" was a key component for moving the community and the conversation along. It was also of invaluable assistance to the BSC task force charged with investigating the relationship between DCRM and RDA and making recommendations for the way forward; it was an influential component of the task force's final report. ${ }^{5}$

At the ALA Midwinter 2011 meeting of the Bibliographic Standards Committee, John Attig and Robert Maxwell presented a discussion paper entitled "Reconsidering DCRM in the Light of RDA." The paper outlined four possible options for ways that DCRM could be integrated with RDA. At that meeting, a majority consensus formed that making RDA the basis for particular instructions in DCRM, but applying RDA in an ISBD structure and continuing to organize DCRM by ISBD areas and elements (the discussion paper's "Option 2"), was most attractive. This approach was seen as the most expedient given that, for some years to come, library cataloging records would still be encoded using the MARC format and the MARC format is organized by ISBD area. However, at the preconference discussion session, this topic engendered a lively debate, with growing support for making RDA the basis for all aspects of DCRM (the discussion paper's "Option 1").

Arguments were made for both options. Those arguments favoring Option 2 presented an easier, "path of least resistance," approach. By keeping the current ISBD organization, using existing DCRM language, and making changes only where needed so that the outcome is congruent with RDA instructions, much faster creation and distribution of RDA-adherent DCRMs would be possible. The component manuals in preparation (for Music, Graphics, Manuscripts, and Cartographic Materials) are, by and large, far enough along that reorganizing at this stage would seriously delay publication. Continued ISBD organization, at least for the short

5. www.rbms.info/committees/bibliographic_standards/dcrm/rda/dcrm-rda.html [accessed 25 March 2013]. 
term, would enable the editorial teams to continue on their current timelines for publication.

Arguments in favor of Option 1 recognized that eventual reorganization according to a Functional Requirements for Bibliographic Records (FRBR) structure is inevitable, and, while issuing DCRM manuals with ISBD organization may be expedient in the short run, it will create more work for future editorial teams in the long run. Delaying organization by FRBR for DCRM will make it increasingly difficult for catalogers to use DCRM as RDA becomes more and more prevalent in libraries nationwide. Not only will this be true for experienced catalogers, but it will especially impact rare materials catalogers entering the field who will have to learn two different conceptual frameworks for cataloging instructions.

While, at the end of the discussion session, a straw poll revealed that the participants were divided nearly evenly into three camps (those who favored an interim ISBD revision, those who favored a complete revision based on RDA, and those who were undecided), the discussion showed the tide had clearly shifted since the Attig-Maxwell paper was first presented and that the future of DCRM lay not in preserving the structures of the past but in embracing and, whenever possible, influencing the development of RDA.

\section{Beyond MARC: Metadata for Digital Resources}

The workshop, "Beyond MARC: Metadata for Digital Resources," introduced attendees to the broader environment of metadata used in libraries, archives, and museums today. Workshop leaders discussed the evolution of metadata standards and the rationale for moving beyond MARC to describe and package digital resources, namely to facilitate sharing of and access to these resources in the various contexts in which they exist, from local systems (ILS), to group systems (aggregations), to global systems (the web). The workshop demonstrated some of the digital object packaging techniques (including METS (Metadata Encoding and Transmission Standard) and BagIt for sharing digital content), offered a descriptive mapping exercise from MARC to MODS and Dublin Core, and facilitated a management workflow exercise to introduce attendees to key processes commonly used in digital object environments.

Because digital resources usually have a life outside our local systems, it is important that we create metadata that can be easily shared with other systems and that will remain with the resource so that it can be appropriately administered, accessed, and preserved. Therefore, digital resources, or digital objects, as they are often referred to, generally include three categories of metadata: descriptive, structural, and administrative (which includes technical, rights, and ownership 
metadata). Descriptive categories include MARC, MODS, Dublin Core, EAD for archives, and CDWA (Categories for the Description of Works of Art) for museums. Structural metadata can be encoded in METS, which, for digital resources like a digital version of a rare book or photo album, is needed to facilitate navigation of the object. Administrative metadata includes technical metadata about the digital file, or files, in order to know how to preserve a digital object over time; rights metadata, to let users know what they can and cannot do with the object; or information about ownership, which is especially important to include with a digital object living outside its local system.

Our community has developed various non-MARC metadata standards and packaging techniques to wrap up and share our digital resources for purposes of preservation, navigation, and access. Packaging techniques one might select depends on how much content is involved, with whom (or what system) you are sharing them, and what technological capabilities your institution has. The workshop looked at data flows, processes, and tools involved in creating these packages in order to share them.

The goal of sharing digital resources in different contexts is to better surface special collections content in places where users are doing their seeking and finding. Unfortunately, the community standards we use do not always play well with one another (interoperate) or function at the network level.

As catalogers know, even with standards, rules, and local conventions, descriptive practices can vary from institution to institution. This is compounded when trying to combine records across different institutions, such as in aggregations like WorldCat. This can become even more significant when bringing records together from across communities, such as in aggregations or subject portals that include library, archive, and museum content, all of which are created using different descriptive standards and practices. To address this, our community has developed mappings from one standard to another and uses XML transformations to harmonize metadata in different formats. The workshop participants were introduced to mapping concepts and carried out a mapping exercise. The goal of this was to demonstrate the variations and issues that can arise when mapping from one standard to another, even when using available mapping transforms.

Ultimately, true metadata interoperability is difficult to achieve. As a community, we have had success working at local and group levels using our own standards, but our resources are still largely hidden from the web. The leaders of the workshop suggested that the promise of linked data is that the structured metadata we have created so far will enable our community to make linkages between our digital 
resources through network-level protocols and increase the discoverability of those resources at the global level. The linked data revolution has the potential to do what we have been trying to do in technical services — and specifically in digital collections-for years; that is, to have our access and discovery metadata interoperating at the network level.

The workshop wrapped up with a management workflow exercise that engaged participants in considering the big picture of packaging and sharing digital resources. This exercise seemed to be enjoyed by all and brought together at the macro level all of the detailed issues that had been touched on throughout the day.

\section{Conclusion}

Clearly, the FUTURES! preconference presented a wide array of topics of significant interest from a technical services standpoint, from RDA to linked open data, from non-MARC metadata schemas to the vital role that technical services plays in enabling digital humanities.

With the advent of RDA and BIBFRAME-which, unfortunately, was not unveiled until after the preconference-technical services librarians are well placed to be leaders in the revolution of library services. This is especially true of special collections technical services practitioners, since much of the "stuff" upon which digital humanities research is built, whether analog or digital, is already being collected, housed, described, and preserved within our institutions. It is our duty to make that research material available in the widest possible sense so that we will continue to be vital partners in the expansion of knowledge and scholarship.

As national cataloging standards migrate to RDA, rare materials catalogers have a distinct advantage over our general materials counterparts in that many of the most radical departures from AACR, such as greater faithfulness to the source in transcription, are already codified in the objectives and principles of DCRM. If we press that advantage and seize opportunities to shape RDA to better serve our community, we will be seen as leaders looking to the future, not as reluctant followers stuck in the traditions of the past.

Technical services units are natural players in implementing new modes of description, building digital collections, and facilitating online access. We can be strong leaders in the digital futures we heard about at this conference by embracing the changes that are already facing us. We should be engaging in the development and implementation of emerging descriptive standards and practices, initiating digitization projects and services, and continuing to focus on access, in whatever new forms it make take-all things we already do. 


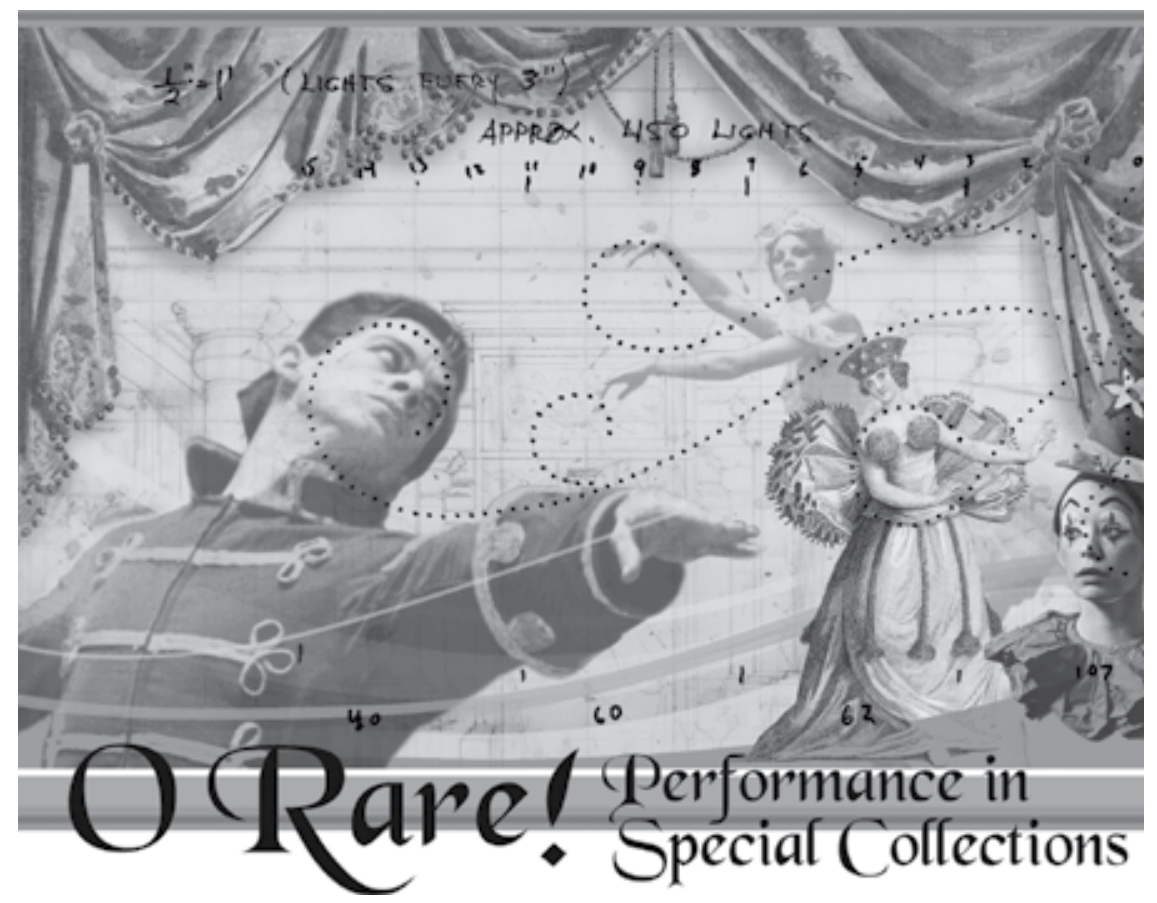

\section{THE 54TH ANNUAL RBMS PRECONFERENCE JUNE $23-26,2013$ | MINNEAPOLIS, MN}

The time has come to talk of many things - of theater, and dance, and musical arts; of laboratories and magic; and why an artifact has a trace; and whether digital facsimiles have wings.

Discussion and delight will commence at the 54th Annual RBMS Preconference. Center stage will be the themes of performance in libraries and libraries as performance. Whether you are a born actor or have serious stage fright; consider this preconference your backstage pass to success.

\section{TICKETS NOW ON SALE! http://www.preconference.rbms.info/}

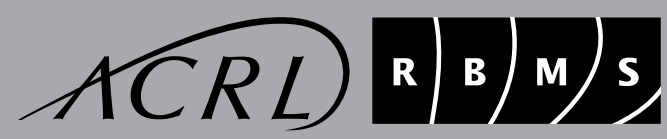

